\title{
Low cumulative incidence of proliferative retinopathy in childhood-onset type 1 diabetes: a 24-year follow-up study
}

\author{
T. Skrivarhaug • D. S. Fosmark • L. C. Stene • \\ H.-J. Bangstad $\cdot$ L. Sandvik $\cdot$ K. F. Hanssen • G. Joner
}

Received: 17 March 2006 / Accepted: 30 May 2006 /Published online: 29 August 2006

(C) Springer-Verlag 2006

\begin{abstract}
Aims/hypothesis We estimated cumulative incidence of proliferative diabetic retinopathy (PDR) and risk factors for developing diabetic retinopathy (DR) in childhoodonset type 1 diabetes.

Materials and methods A sample of 294 patients with childhood-onset type 1 diabetes $(<15$ years) diagnosed in Norway between 1973 and 1982 was examined for retinopathy at baseline between 1989 and 1990 and at follow-up from 2002 to 2003 . At follow-up, mean age was
\end{abstract}

T. Skrivarhaug $(\bowtie) \cdot$ H.-J. Bangstad $\cdot$ G. Joner

Department of Paediatrics, Ullevål University Hospital,

N-0407 Oslo, Norway

e-mail: torild.skrivarhaug@medisin.uio.no

D. S. Fosmark

Department of Ophthalmology, Ullevål University Hospital,

Oslo, Norway

L. C. Stene

Division of Epidemiology, Norwegian Institute of Public Health,

Oslo, Norway

L. Sandvik

Centre for Clinical Research, Ullevål University Hospital,

Oslo, Norway

K. F. Hanssen

Department of Endocrinology,

Aker University Hospital and University of Oslo,

Oslo, Norway

T. Skrivarhaug $\cdot$ D. S. Fosmark $\cdot$ L. C. Stene $\cdot$ H.-J. Bangstad

K. F. Hanssen · G. Joner

Diabetes Research Centre, Aker and Ullevål University Hospitals, Oslo, Norway
33 years (range: $21-44$ ), mean diabetes duration 24 years (19-30) and total person-time contributed 7,152 personyears. Retinal photographs were taken at baseline and follow-up. Associations between baseline factors and PDR were estimated using Cox regression models.

Results Overall, 262 of 294 (89.1\%) developed DR from diabetes onset, of whom 31 developed PDR. The 25-year cumulative incidence of PDR was $10.9 \%$ (95\% CI $7.3-$ 14.5). Among 194 without retinopathy at baseline, 163 (84\%) developed DR and nine (5\%) progressed to PDR. Among 97 patients with non-proliferative DR at baseline, $19(20 \%)$ progressed to PDR. Significant predictors for developing PDR were retinopathy at baseline (relative risk $[R R]=3.71,95 \%$ CI $1.59-8.68), \mathrm{HbA}_{1 \mathrm{c}}(\mathrm{RR}=2.05,1.44-$ $2.93)$, and triglycerides $(\mathrm{RR}=1.55,1.06-1.95)$.

Conclusions/interpretation Nine out of every ten patients diagnosed with type 1 diabetes developed DR, but only one out of ten developed PDR within their first 25 years of diabetes duration. The cumulative incidence of PDR is lower than previously reported from other countries. Potentially modifiable risk factors predict the development of DR and PDR.

Keywords Cohort study - Diabetic retinopathy Epidemiology · Proliferative diabetic retinopathy · Risk factors · Triglycerides · Type 1 diabetes
Abbreviations
DCCT Diabetes Control and Complications Trial
DR diabetic retinopathy
NPDR non-proliferative diabetic retinopathy
PDR proliferative diabetic retinopathy
$\mathrm{RR}$ relative risk 


\section{Introduction}

Retinopathy is the most common microvascular complication of diabetes [1]. It has previously been identified in virtually all people with type 1 diabetes. Diabetic retinopathy (DR) is usually present for many years before eventual progression to visual impairment makes it apparent to the patient. It is the leading cause of acquired blindness among people of working age in the Western world [2-6]. The medical, social and financial impact of this disease is substantial.

Klein et al. reported an overall 10-year cumulative incidence of any retinopathy of $89.3 \%$ in insulin-treated patients with diabetes diagnosed before the age of 30 years [7], with a corresponding 10-year cumulative incidence of proliferative diabetic retinopathy (PDR) of $29.8 \%$ [7]. In type 1 diabetes, previous studies have demonstrated a cumulative incidence of PDR of 20 to $40 \%$ after 20 to 25 years of disease duration [8-13]. PDR was reported to develop in as many as $70 \%$ of youth-onset patients after 30 years of diabetes diagnosed in the years 1950 to 1960 [11]. Recently a Danish study demonstrated a decrease in the cumulative incidence of PDR after 20 years of diabetes duration, from 31.2 to $12.5 \%$, over the past 35 years [12]. A Swedish study also reported a declining trend with increasing calendar year of diagnosis [13].

Numerous studies $[8,11-20]$ have described the prevalence and incidence of DR in type 1 diabetes and its relationship to various characteristics. However, only a few population-based studies of retinopathy in subjects with childhood-onset type 1 diabetes are available [13, 15, 19, 20]. Observational studies from dedicated centres $[12,13]$ have argued that the individual risk of developing microvascular complications has declined in recent years as a consequence of improvement in diabetes management. It is of concern, however, that the results from specialised centres cannot be applied to routine diabetes care. In this report, we describe the cumulative incidence of PDR after 25 years of diabetes duration, the ability of baseline factors to predict the development of DR and PDR, and the ability of baseline factors to predict progression from DR at baseline to PDR during follow-up in a national cohort.

\section{Subjects, materials and methods}

Patients

All new-onset cases of type 1 diabetes occurring in Norwegian children below 15 years of age from 1973 through to 1982 were registered retrospectively by the Norwegian Childhood Diabetes Registry between 1985 and 1986 with a high level of ascertainment [21]. In 1989, 600 randomly selected patients among the 1,868 who were alive and still living in Norway were invited to a clinical examination for assessment of diabetic complications as previously reported [15]. Of the 368 subjects who participated in the baseline examination between 1989 and 1990, 355 were eligible for a follow-up examination in the years 2002 to 2003. Figure 1 illustrates the design of the current study including the number of patients who emigrated and died during follow-up. Mortality and emigration by 1989 and 2001 were assessed by linkage to the official population registry of Norway [22].

The current analysis includes the 294 participants in 2002 and 2003 who provided retinal photographs sufficient for classifying patients with regard to retinopathy. Written informed consent was obtained from all participants, and the study was approved by the Regional Ethics Committee and the National Data Inspectorate.

Clinical examination and collection of biological samples

Baseline examinations were conducted between 1989 and 1990 and follow-up examinations from 2002 to 2003. One trained physician performed all measurements with standardised procedures and equipment according to a predefined protocol at baseline (G. Joner) and at follow-up (T. Skrivarhaug). The participants belonged to different hospital catchment areas, and some of them had their medical contact with a general practitioner. The investigator visited 24 different hospitals all over Norway. The examination included a medical history, blood pressure measurements, collection of overnight timed urine, random venous blood samples and fundus photography. The medical history interview emphasised use of antihypertensive medications, lipid-lowering medication and smoking habits. Patients were classified as smokers when smoking one or more cigarettes per day. Blood pressure was measured twice with the patient in the sitting position after $10 \mathrm{~min}$ of rest, using the same mercury sphygmomanometer for all the patients. The mean of two readings was used for analysis. Three overnight timed urine samples were collected at home. The characteristics of the patients examined in this study are presented in Table 1.

\section{Retinal assessment}

Retinal photography was performed in mydriasis using cyclopentolate $1 \%$ and epinephrine (adrenaline) 10\%. Colour retinal photographs were taken of both eyes by a single operator (T. Skrivarhaug) using a non-mydriatic $45^{\circ}$ retinal camera (45NM-CR; Canon, Tokyo, Japan). The photo with best quality was selected for retinopathy reading. The standard procedure of centring the photograph 
Fig. 1 Flow chart showing the design of the study

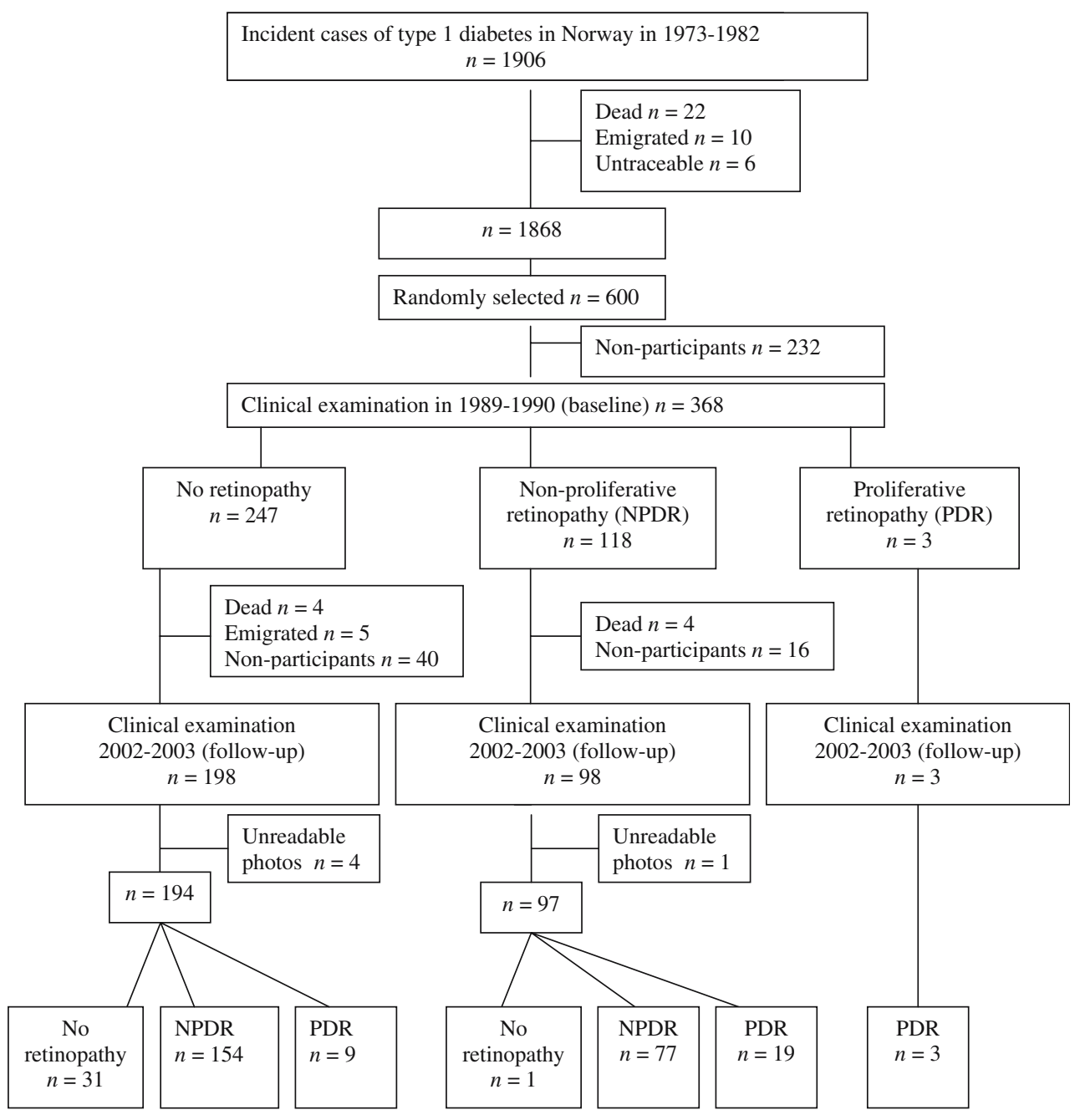

The presence and severity of DR were assessed from these $45^{\circ}$ retinal photographs obtained with a wide-angle camera and scored centrally, without knowledge of the subject's identity, by an ophthalmologist (D. S. Fosmark). Retinopathy was classified as non-proliferative DR (NPDR) NY, USA).

Table 1 Demographic characteristics and putative risk factors for DR among the 294 (157 male and 137 female) patients with childhood-onset type 1 diabetes examined both in 1989-1990 and in 2002-2003

Baseline (1989-1990)

$19.3(8.0-30.7)$

Age (years)

Duration of diabetes (years)

$\mathrm{HbA}_{1 \mathrm{c}}(\%)^{a}$

Total cholesterol $(\mathrm{mmol} / \mathrm{l})^{a}$

Triglycerides $(\mathrm{mmol} / \mathrm{l})^{a}$

Systolic blood pressure $(\mathrm{mmHg})$

Diastolic blood pressure $(\mathrm{mmHg})$

$\mathrm{AER}^{a}$

Current smokers, $n(\%)$

Antihypertensive treatment, $n(\%)$

Lipid-lowering medication, $n(\%)$
$11.1(6.3-17.3)$

$8.5(5.0-14.6)$

$5.1(3.3-9.7)$

$1.1(0.3-6.9)$

$122(17.1)$

79 (13.4)

$5.0(1.0-300.5)$

$133(45.2)$

$0(0)$

$0(0)$
Follow-up (2002-2003)

$32.6(20.9-44.0)$

$24.3(19.3-29.9)$

$8.0(4.9-13.7)$

$5.2(3.5-9.9)$

$1.1(0.4-7.5)$

$126(14.1)$

79 (9.5)

$4.0(1.0-1,376)$

$123(41.8)$

49 (16.7)

$21(7.0)$

Data are presented as mean (SD), mean (range) or ${ }^{a}$ median (range)

Mean age at diabetes onset was 8.1 years (range: $0.4-14.9$ years) 
Table 2 The diabetic retinopathy disease severity scale

\begin{tabular}{ll}
\hline $\begin{array}{l}\text { Disease severity } \\
\text { level }\end{array}$ & $\begin{array}{l}\text { Findings on } 45^{\circ} \text { retinal photographs in } \\
\text { mydriasis }\end{array}$ \\
\hline $\begin{array}{l}\text { No apparent } \\
\text { retinopathy } \\
\text { Mild NPDR } \\
\text { Moderate NPDR }\end{array}$ & $\begin{array}{l}\text { No abnormalities } \\
\text { Microaneurysms only } \\
\text { Severe NPDR }\end{array}$ \\
$\begin{array}{l}\text { Any of the following: } \\
\text { more than } 20 \text { intraretinal haemorrhages in } \\
\text { each of four quadrants } \\
\text { definitive venous beading in two or more } \\
\text { quadrants } \\
\text { prominent intraretinal microvascular } \\
\text { abnormalities in one or more quadrant } \\
\text { and no signs of PDR } \\
\text { One or more of the following: } \\
\text { neovascularisation } \\
\text { vitreous haemorrhage } \\
\text { photocoagulation scars }\end{array}$ \\
\end{tabular}

or PDR adapting a clinical method [23]. The DR disease severity levels are listed in Table 2. Both eyes were assessed consecutively; the status of the worse eye deciding the level of retinopathy. Patients with fibrous proliferations, vitreous haemorrhage or scars from photocoagulation were assigned to the proliferative category. Time of onset of PDR was defined as the first eye examination when the lesions were observed, according to medical records. All patients diagnosed with PDR had undergone at least one eye examination (and usually several) during the preceding 2 years with a negative diagnosis for PDR. Blindness was defined as best visual acuity $\leq 0.05$ in the better eye. As stereo retinal photographs were not taken, it was not possible to assess retinal thickening and elevation directly. Hence, macular oedema was not gradable in this study.

\section{Laboratory analyses}

All laboratory analyses were done centrally. $\mathrm{HbA}_{1 \mathrm{c}}$ was measured by HPLC (Variant; Bio-Rad, Richmond, CA, USA); the intra-assay $\mathrm{CV}$ was $<3 \%$. The normal range for $\mathrm{HbA}_{1 \mathrm{c}}$ in the reference laboratory in 1989-1990 was 4.5 to $6.1 \%$, interassay $\mathrm{CV} 3 \%$. Lipids were measured with standard enzymatic methods and urinary albumin concentration with immunoturbidimetry. AER was calculated on the basis of concentration, collection time and volume. Persistent microalbuminuria and overt nephropathy were defined as AER 15 to $200 \mu \mathrm{g} / \mathrm{min}$ and AER $>200 \mu \mathrm{g} / \mathrm{min}$, respectively, in at least two out of three consecutive overnight urine samples [24].

Statistical analysis

We estimated the cumulative incidence of PDR from diabetes onset until follow-up, using a Kaplan-Meier plot. To assess declining incidence of PDR with year of diagnosis, the patients were divided into two groups: 1973-1977 $(n=133)$ and 1978-1982 $(n=161)$. Cox regression analysis was used to estimate the hazard ratio for association between baseline factors and PDR. The following variables were analysed: sex, age, age at diabetes onset, diabetes duration, smoking status, arterial blood pressure, AER, $\mathrm{HbA}_{1 \mathrm{c}}$, triglycerides and total cholesterol. Variables with a $p$-value $<0.20$ were then included simultaneously in a multiple regression model. In the analysis of predictive risk factors for PDR, the three subjects with PDR at baseline were not included. Since we did not know the exact time of onset of NPDR, the assessment of potential predictors of retinopathy among patients without DR at baseline was analysed similarly using logistic regression. Findings with a $p$-value $<0.05$ were considered statistically significant. Analyses were performed with SPSS (Version 12). Patient characteristics at baseline, divided into participants and nonparticipants at follow-up, were compared by means of Student's $t$-test (two-tailed) and with a chi-square test.

Non-participants 1989-1990

The 368 subjects who participated in the examination in the years 1989 to 1990 were slightly younger, had slightly shorter disease duration and significantly lower $\mathrm{HbA}_{1 \mathrm{c}}$ than the 232 who did not participate (mean $\mathrm{HbA}_{1 \mathrm{c}} 8.9$ vs $9.5 \%$, $p=0.004$ ), but the distribution of sex and age at onset of diabetes was similar in the two groups.

Non-participants 2002-2003

There were no significant differences regarding demographic characteristics, $\mathrm{HbA}_{1 \mathrm{c}}$, blood pressure or microvascular complications at baseline among the 299 subjects who participated in the clinical examination in 2002 and 2003, compared with the 69 non-participants (Table 3).

\section{Sensitivity analysis of non-participation}

Using assumptions based on external data, we performed a sensitivity analysis in order to assess the potential influence of selection bias due to non-participation and other losses to follow-up (deaths and emigration) on our estimated risk of complications. The total risk in the full cohort of participants and non-participants is a weighted average of the 
Table 3 Characteristics and $\mathrm{HbA}_{1 \mathrm{c}}$ among 368 patients with childhood-onset type 1 diabetes, split into participants or non-participants in 2002-2003

\begin{tabular}{llll}
\hline & Participants in 2002-2003 & Non-participants in 2002-2003 \\
\hline$n$ & 299 & 69 & $45(65.2)$ \\
Gender, males, $n(\%)$ & $160(53.5)$ & $18.1(9.5-27.2)$ & 0.08 \\
Age (years) & $19.3(3.4-30.7)$ & $10.5(6.2-16.3)$ & 0.06 \\
Duration of diabetes (years) & $11.1(6.3-17.3)$ & $7.6(1.9-14.9)$ & 0.16 \\
Mean age at diabetes onset (years) & $8.3(0.4-14.9)$ & $113(30.0)$ & 0.21 \\
HbA $_{1 \mathrm{c}}(\%)$ & $8.8(1.9)$ & $76(22.4)$ & 0.38 \\
Systolic blood pressure (mmHg) & $114(27.6)$ & $20(29.0)$ & 0.82 \\
Diastolic blood pressure (mmHg) & $74(19.4)$ & $0(0)$ & 0.46 \\
NPDR, $n$ (\%) & $98(32.7)$ & $8(11.6)$ & 0.64 \\
PDR, $n(\%)$ & $3(1.0)$ & $0(0)$ & 1.00 \\
Persistent microalbuminuria, $n(\%)$ & $34(11.4)$ & $1(0.3)$ & 0.87 \\
Proteinuria, $n$ (\%) & & 1.00 \\
\hline
\end{tabular}

These data are based on status and measurements between 1989 and 1990. Data are presented as mean (SD) or mean (range)

observed risk of complications among participants and the corresponding risk among non-participants. This total risk can then be estimated under conservative assumptions regarding the risk among non-participants.

Data from non-participants in the examination in 1990 indicated that the mean $\mathrm{HbA}_{1 \mathrm{c}}$ was $9.5 \%$ among nonparticipants compared with $8.9 \%$ among participants [15], i.e. a difference of $0.6 \%$. For the purpose of the sensitivity analysis, we conservatively assume that the non-participants in our study had a mean $\mathrm{HbA}_{1 \mathrm{c}} 1 \%$-point higher than the participants and that $50 \%$ of them had no DR at baseline and the rest had NPDR. Data from the Diabetes Control and Complications Trial (DCCT) [25] indicated a $75 \%$ increase in risk of PDR per 1\%-point increase in $\mathrm{HbA}_{1 \mathrm{c}}$ during a mean follow-up of 6.5 years. We therefore conservatively assume that the non-participants had $75 \%$ higher risk of PDR as compared with the participants.

\section{Results}

Characteristics of study group

Two hundred and ninety-four patients were followed for a mean of 24.1 years (range: 19.3-29.9 years), contributing a total of 7,152 person-years. Overall, 262 of 294 patients (89.1\%) developed retinopathy from diabetes onset to follow-up (Table 4), of whom 31 developed PDR. Significantly more males (147 of $157,93.6 \%)$ than females (115 of $137,83.9 \%)$ developed retinopathy $(p=0.009)$. Progression to PDR was similar in men and women (15 of 157 [9.6\%] vs 15 of 157 [11.7\%], $p=0.57$ ). The event rate for PDR from diabetes onset was 4.5 per 1,000 patient-years. The cumulative incidence of PDR after 25 years of diabetes duration was $10.9 \%$ (95\% CI $7.3-14.5)$. The cumulative incidence of PDR began to increase after 10 years of diabetes (Fig. 2). Mean age at diagnosis of PDR was 27 years (range: 17-41), and mean diabetes duration was 19 years (12-29). Thirty-two patients $(10.9 \%)$ had no retinopathy at follow-up. There was no difference in progression to PDR among those in the two lower quartiles of systolic blood pressure $(<120 \mathrm{mmHg})$ at baseline compared with those in the upper two quartiles ( $\geq 120 \mathrm{mmHg}$ ), either when analysing the group with no DR or NPDR at baseline alone, or both groups together. All $p$-values were $>0.40$.

At follow-up, all subjects were treated with at least two daily insulin injections, except for one woman who had a pancreas transplant (April 2002). Distribution of retinopathy status in regard to number of insulin injections or home monitoring of blood glucose is given in Tables 5 and 6 , respectively. Forty-one of the patients were treated with ACE-inhibitors and eight with angiotensin II receptor antagonists. Among the patients on ACE-inhibitors, at follow-up two had no retinopathy, 26 had NPDR and 13 had PDR. Of the eight patients treated with angiotensin II receptor antagonists, four had NPDR and four PDR.

Table 4 Distribution of retinopathy status at follow-up (2002-2003) in 294 patients (157 male and 137 female) with childhood-onset type 1 diabetes

\begin{tabular}{ll}
\hline Disease severity level & $n(\%)$ \\
\hline No DR & $32(10.9)$ \\
NPDR & $231(78.6)$ \\
Mild & $126(42.9)$ \\
Moderate & $75(25.5)$ \\
Severe & $30(10.2)$ \\
PDR & $31(10.5)$ \\
\hline
\end{tabular}




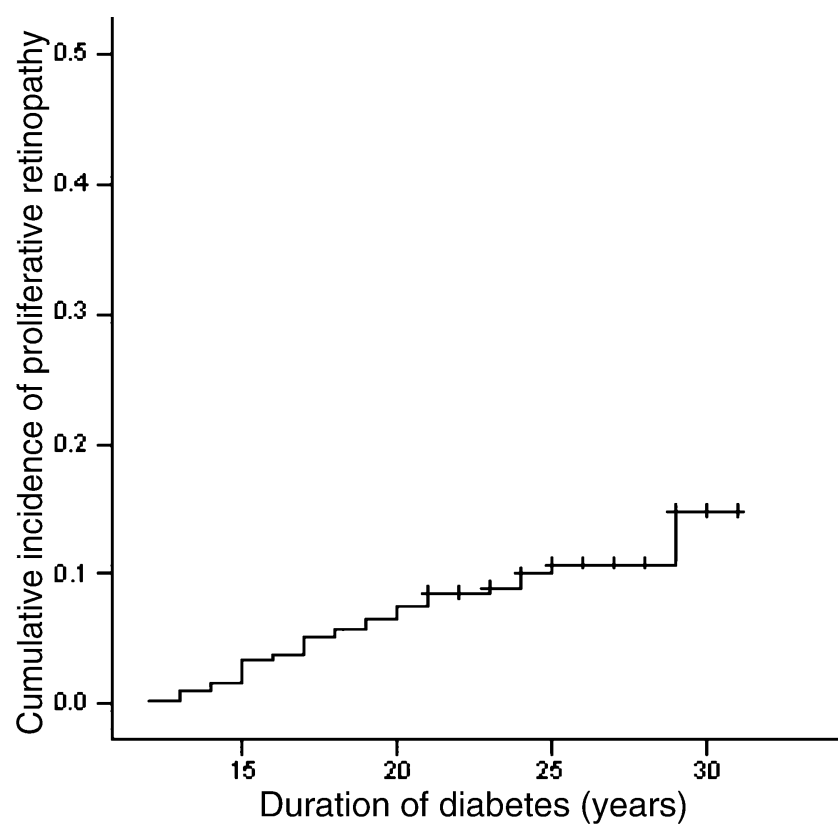

Fig. 2 Cumulative incidence of PDR (31 events) in 294 patients with childhood-onset type 1 diabetes diagnosed from 1973 to 1982

The one female and seven males who died between 1990 and 2002 were all under 30 years of age at the time of death (mean: 21 years), and the mean duration of diabetes was 14 years. The causes of death were pulmonary embolism during pregnancy $(n=1)$, diabetic ketoacidosis $(n=3)$, hypoglycaemia $(n=2)$, suicide $(n=1)$ and sudden death $(n=1)$.

According to medical records, none of them had developed PDR at the time of death, and four of them had NPDR [22].

No retinopathy at baseline

Among 194 patients without retinopathy at baseline, 154 (79.4\%) and nine (4.6\%) had developed NPDR and PDR, respectively, at follow-up. Clinical data registered at followup are given in Table 7.

Retinopathy at baseline

Among 97 patients with NPDR at baseline, $19(20 \%)$ developed PDR. Three of them were blind. Blindness was diagnosed at young adult age (19, 27 and 28 years) and they were all females. In one patient diagnosed with NPDR at baseline, no lesions could be found at follow-up. Clinical data registered at follow-up are given in Table 7 .

PDR at baseline

The three patients with PDR at baseline, two men and one woman, were 20, 24 and 17 years, respectively, at the time of PDR diagnosis. They were all younger than 10 years at diabetes onset (4, 6 and 9 years old). At follow-up, one of them had microalbuminuria. He was the only one smoking and the only one treated with antihypertensive medication (ACE-inhibitor) and statins. The two others had normoalbuminuria.

Predictors for PDR

Significant predictors at baseline for the development of PDR were $\mathrm{HbA}_{1 \mathrm{c}}$ (relative risk $[\mathrm{RR}]=2.05$, 95\% CI 1.442.93, $p<0.001)$, triglycerides $(\mathrm{RR}=1.55,95 \% \mathrm{CI} 1.06-1.95$, $p=0.019)$ and NPDR $(\mathrm{RR}=3.71,95 \%$ CI 1.59-8.68, $p=0.03$ ). Smoking, age, blood pressure, gender, total cholesterol, diabetes duration, age at diabetes onset and AER were not significant predictors for the development of PDR.

Predictors for DR

Logistic regression analyses demonstrated that significant predictors at baseline for the development of any retinopathy were $\mathrm{HbA}_{1 \mathrm{c}}$ (odds ratio=3.25, 95\% CI 1.76-6.02, $p<0.001$ ) and male gender (odds ratio $=2.51,95 \%$ CI $1.06-$ $6.00, p=0.037)$. Smoking, age, blood pressure, triglycerides, total cholesterol, diabetes duration, age at diabetes onset and AER were not significant predictors for the development of DR.

Period of diabetes diagnosis as a predictor of PDR

The cumulative incidence of PDR after 24 years of diabetes duration was $12.8 \%$ among those diagnosed between 1973 and 1977 and $7.9 \%$ among those diagnosed between 1978

Table 5 Insulin treatment and retinopathy status at follow-up in the 294 patients (157 male and 137 female) with childhood-onset type 1 diabetes, examined both in 1989-1990 and in 2002-2003

\begin{tabular}{|c|c|c|c|c|}
\hline & No DR & NPDR & PDR & Total \\
\hline$<3$ insulin injections/day, $n(\%)$ & $3(9)$ & $9(4)$ & $0(0)$ & $12(4)$ \\
\hline$\geq 3$ insulin injections/day, $n(\%)$ & $25(78)$ & $202(87)$ & $27(87)$ & $254(86)$ \\
\hline Continuous s.c. insulin infusion, $n(\%)$ & $4(13)$ & $19(8)$ & $4(13)$ & $27(9)$ \\
\hline Pancreas transplant (April 2002), $n(\%)$ & $0(0)$ & $1(0.4)$ & $0(0)$ & $1(0.3)$ \\
\hline Total number of patients, $n(\%)$ & $32(100)$ & $231(100)$ & $31(100)$ & $294(100)$ \\
\hline
\end{tabular}


Table 6 Home monitoring of blood glucose and retinopathy status at follow-up in the 294 patients (157 male and 137 female) with childhood-onset type 1 diabetes examined both in 1989-1990 and in 2002-2003

\begin{tabular}{lllll}
\hline Home monitoring & No DR & NPDR & PDR & Total \\
\hline $\begin{array}{l}\text { Never, } n(\%) \\
\text { Seldom, } n(\%)\end{array}$ & $11(3)$ & $18(8)$ & $4(13)$ & $23(8)$ \\
$\begin{array}{l}1-5 \text { times a day, } \\
n(\%)\end{array}$ & $13(41)$ & $82(40)$ & $12(39)$ & $115(39)$ \\
$\begin{array}{l}n \text { times a day, } \\
n(\%)\end{array}$ & $7(22)$ & $33(14)$ & $4(13)$ & $44(15)$ \\
\begin{tabular}{l} 
Total, $n(\%)$ \\
\hline
\end{tabular} & $32(100)$ & $231(100)$ & $31(100)$ & $294(100)$ \\
\end{tabular}

and 1982. This difference was not statistically significant (log-rank test, $p=0.13$ ).

Sensitivity analysis of non-participation

We did a sensitivity analysis to assess the potential influence of selection bias due to non-participation and other losses to follow-up on our estimated risk of complications. The total risk in the full cohort of participants and non-participants is a weighted average of the observed risk of complications among participants and the corresponding, unobserved risk among non-participants. The total risk can then be estimated under various assumptions regarding the hypothetical risk among nonparticipants. If the cumulative risk of PDR was 30 to $80 \%$ higher among non-participants than among participants (corresponding to $14.2-19.6 \%$ among non-participants), we calculated that the cumulative risk of PDR in the full cohort would be 12.5 to $15.4 \%$.

\section{Discussion}

We found a cumulative incidence of PDR of $10.9 \%$ within the first 25 years of type 1 diabetes, which is lower than previously reported from other countries. The cumulative incidence of PDR of 20 to $40 \%$ after 25 years of diabetes duration reported from other studies [8-13] is in great contrast to the decline in cumulative incidence reported in cohorts diagnosed after 1970 [12, 13]. We could not show any difference in risk of PDR in those diagnosed between 1973 and 1977 compared with those diagnosed between 1978 and 1982, but there is a short time-span between the groups and they were both diagnosed before $\mathrm{HbA}_{1 \mathrm{c}}$ measurement was introduced.

Krolewski et al. [8] reported in 1986 the risk of PDR to be almost non-existent during the first 10 years of diabetes, rising within a short span of 5 years to its maximum level, and remaining constant at that level ( $\sim 30$ per 1,000 personyears) for the next 25 years. We found the event rate of PDR from diabetes onset to be 4.5 per 1,000 person-years, indicating a lower risk of PDR than in Krolewski's study. The first case of PDR appeared after 12 years of diabetes duration. This is in keeping with several other surveys indicating that PDR rarely occurs before 10 years of diabetes duration $[8,13]$.

In our study, $\mathrm{HbA}_{1 \mathrm{c}}$ measured at baseline emerged as an important predictor of the incidence of retinopathy and

Table 7 Clinical data and characteristics in 2002-2003 of the subjects with no DR in 1989-1990 and of the subjects with NPDR in 1989-1990

\begin{tabular}{|c|c|c|c|c|c|}
\hline & $\begin{array}{l}\text { No DR } \\
2002-2003\end{array}$ & $\begin{array}{l}\text { NPDR } \\
2002-2003\end{array}$ & $\begin{array}{l}\text { PDR } \\
2002-2003\end{array}$ & $\begin{array}{l}\text { Blind } \\
2002-2003\end{array}$ & $\begin{array}{l}p(\mathrm{PDR}+\mathrm{blind} \mathrm{vs} \\
\text { no } \mathrm{DR}+\mathrm{NPDR})\end{array}$ \\
\hline \multicolumn{6}{|c|}{ No DR at baseline ( $n=194,102$ male and 92 female) } \\
\hline$n$ & 31 & 154 & 9 & 0 & \\
\hline Males, $n(\%)$ & $10(32)$ & $90(58)$ & $2(22)$ & $0(0)$ & 0.09 \\
\hline Antihypertensive treatment, $n(\%)$ & $2(6)$ & $18(12)$ & $4(44)$ & $0(0)$ & 0.015 \\
\hline Lipid-lowering treatment, $n(\%)$ & $1(3)$ & $6(4)$ & $2(22)$ & $0(0)$ & 0.058 \\
\hline Microalbuminuria, $n(\%)$ & $2(6)$ & $16(10)$ & $3(33)$ & $0(0)$ & 0.060 \\
\hline Proteinuria, $n(\%)$ & $0(0)$ & $6(4)$ & $3(33)$ & $0(0)$ & 0.005 \\
\hline Smoking 1989-1990, $n(\%)$ & $12(39)$ & $60(39)$ & $5(56)$ & $0(0)$ & 0.49 \\
\hline Smoking 2002-2003, $n(\%)$ & $10(32)$ & $60(39)$ & $4(44)$ & $0(0)$ & 0.73 \\
\hline \multicolumn{6}{|c|}{ NPDR at baseline ( $n=97,53$ male and 44 female) } \\
\hline$n$ & 1 & 77 & 16 & 3 & \\
\hline Males, $n(\%)$ & $0(0)$ & $42(54)$ & $11(69)$ & $0(0)$ & 0.95 \\
\hline Antihypertensive treatment, $n(\%)$ & $0(0)$ & $12(16)$ & $12(75)$ & $3(100)$ & $<0.001$ \\
\hline Lipid-lowering treatment, $n(\%)$ & $1(100)$ & $6(8)$ & $4(25)$ & $0(0)$ & 0.22 \\
\hline Microalbuminuria, $n(\%)$ & $0(0)$ & $16(21)$ & $4(25)$ & $0(0)$ & 1.00 \\
\hline Proteinuria, $n(\%)$ & $0(0)$ & $3(4)$ & $5(31)$ & $2(67)$ & $<0.001$ \\
\hline Smoking 1989-1990, $n(\%)$ & $0(0)$ & $43(56)$ & $10(63)$ & $2(67)$ & 0.71 \\
\hline Smoking 2002-2003, $n(\%)$ & $0(0)$ & $38(49)$ & $9(56)$ & $0(0)$ & 0.88 \\
\hline
\end{tabular}


PDR, which is consistent with previous studies. The strong association between $\mathrm{HbA}_{1 \mathrm{c}}$ and the appearance and progression of retinopathy has been observed in many studies based on clinical patient groups [18, 26, 27]. The Wisconsin Epidemiological Study of Diabetic Retinopathy $[14,28]$ showed the predictive importance of $\mathrm{HbA}_{1 \mathrm{c}}$ in a population-based, prospective study. The close, probably causal nature of this link has been affirmed in type 1 diabetes in the DCCT [25].

Duration of diabetes and severity of hyperglycaemia have consistently been reported to be important risk factors for the development of retinopathy [29]. However, if retinopathy is present, duration of diabetes appears to be a less important factor for the progression from earlier to later stages of retinopathy, but the degree of hyperglycaemia remains important as a risk factor for progression [29]. It has been reported $[9,19]$ that the effect of diabetes duration on the presence of DR is not uniform; in persons who developed diabetes before reaching 13 years of age, duration had less effect than in persons who were 13 years or older at diabetes onset. In our study, when diabetes duration was included in the multivariate models, it was no longer a significant risk factor for development of DR or PDR. Eighty-six per cent of our participants developed diabetes when younger than 13 years.

The observation that people with non-proliferative lesions are more likely to develop PDR was not surprising, as these patients have already gone through the initial stages of retinopathy, as reported previously $[16,30,31]$.

The results of previous studies on the relationship between blood lipids and retinopathy in patients with type 1 diabetes have been inconsistent [32-35]. Elevated levels of triglycerides at baseline have been reported as a risk factor for PDR [29], consistent with our results. Recent papers stress the association between triglycerides and different microvascular complications [36, 37], suggesting that traditional cardiovascular risk factors are also operative in microvascular disease. The present study supports this association. Associations between retinopathy and levels of triglyceride-rich lipoproteins may partly be explained by prothrombotic effects of the latter on vascular cells [38]. We did not find cholesterol to be associated with PDR. One possible explanation of this finding is that raised triglycerides, but not cholesterol, are associated with insulin resistance, which may play a role in the development of albuminuria in type 1 diabetes [39].

Whether insulin resistance contributes to the pathogenesis of PDR is presently unknown. A potential problem for the interpretation of our triglyceride data is that the patients were not fasting, and type and time since last meal was not standardised.
We found that being male was a significant predictor for developing DR but not PDR. This is in keeping with the publication of Orchard et al. [11]. Whether this is due to genetic, hormonal or environmental factors is unknown.

Observational studies have failed to show consistent associations between systolic or diastolic blood pressure at baseline and incidence or progression of DR $[1,16,40]$.

We could not find a statistically significant association of baseline arterial pressure with DR or progression to PDR in our study. The effect of tobacco smoking on DR has long been contested [41-43]. In our study we did not find smoking to be a predictor for development of DR or PDR.

A previous study has demonstrated that the progression of DR can be prevented or delayed in normotensive type 1 diabetic patients treated with ACE-inhibitors [44]. Other trials $[45,46]$ do not support the notion that ACE-inhibitors have specific effects on the course of retinopathy. In our study, 41 patients were treated with ACE-inhibitors and eight with angiotensin II receptor antagonists. We can only speculate whether our results would have differed without this medical treatment.

There is no information on the follow-up retinal status of the non-participating survivors. Some of the challenges facing clinical studies on retinopathy include how to detect DR and how to measure its severity. The retinal photos were graded by the International Clinical Diabetic Retinopathy Severity Scale [23]. The risk of disease progression associated with each of the stages of this simplified classification system [23] can be correlated with Early Treatment Diabetic Retinopathy Study [30] and Wisconsin Epidemiological Study of Diabetic Retinopathy [47] findings. The most important groups in the classification system are those indicating that a patient is at risk of vision loss from DR. The levels of grading of retinopathy (Table 2) include three with relatively low risk and two with significant risk of visual loss. Eyes with severe NPDR are at high risk of developing PDR [30].

We consider it important that our study is based on patients from all over Norway, belonging to different hospital catchment areas, thus reducing the lack of generalisability of results based on patients from single and often specialised treatment centres. This comes at the cost of higher losses to follow-up because patients had to attend an extra clinical examination for the purpose of our study. Although we lost a proportion of participants from the first randomly selected 600 patients, the study cohort was demonstrated to have epidemiological characteristics similar to the population-based registry of childhood-onset type 1 diabetes [15]. Our sensitivity analysis showed that even if non-participants hypothetically had a higher risk of PDR than the participants, the risk of PDR in the target population was still relatively low. Considering the slow progression of PDR, the long follow-up period is an 
important strength of this study. It should be noted that the retinal photographs are less sensitive and specific than the seven-field retinal photographic method, which has come to be the 'Gold Standard' for epidemiological surveys of DR. The diagnosis of retinopathy is based on two non-stereo photographs of the posterior pole. However, studies have reported this method to be efficient in detecting retinopathy in diabetic patients, and the risk of missing patients with only peripheral retinal changes is small $[48,49]$.

Although $\mathrm{HbA}_{1 \mathrm{c}}$ was the strongest modifiable risk factor for developing retinopathy, current approaches to intensive treatment are not likely, on their own, to completely abolish progression to PDR [25]. In particular, there appears to be no glycaemic threshold below which a patient can be sure to be protected from progression to PDR, indicating that other lines of intervention must be pursued.

In conclusion, we found a lower cumulative incidence of PDR after 25 years of diabetes duration than previously reported from other countries. Our results indicate that prevention of diabetes-related visual impairment depends on active control of blood glucose and serum triglycerides, combined with regular screening for sight-threatening retinopathy, these remaining the best available options for intervention on modifiable risk factors.

Acknowledgements This study was supported by grants from the Norwegian Diabetes Association, Aker Diabetes Research Foundation, Novo Nordisk Fonden and Eastern Norway Regional Health Authority. We thank the diabetic patients all over Norway who participated in the study.

\section{References}

1. Aiello LP, Cahill MT, Wong JS (2001) Systemic considerations in the management of diabetic retinopathy. Am J Ophthalmol 132:760-776

2. Sorsby A (1973) The incidence and causes of blindness in England and Wales, 1963-1968. Report No. 12. Her Majesty's Stationery Office, London, pp 1-72

3. National Society to Prevent Blindness (1980) Vision problems in the US. Data analysis. Definitions, data sources, detailed data tables, analysis, interpretation. National Society to Prevent Blindness, New York, pp 1-46

4. Houston A (1982) Retinopathy in the Poole area: an epidemiological inquiry. In: Eschwege E (ed.) Advances in diabetes epidemiology. INSERM Symposium No. 22. Elsevier, Amsterdam, pp 199-206

5. Klein R, Klein BEK (1985) Vision disorders in diabetes. In: Harris MI, Hamman RF (eds) Diabetes in America. US Gov Printing Office, Washington DC, pp XIII 1-22

6. Taylor HR, Keeffe JE (2001) World blindness: a 21st century perspective. Br J Ophthalmol 85:261-266

7. Klein R, Klein BEK, Moss SE, Cruickshanks KJ (1994) The Wisconsin epidemiologic study of diabetic retinopathy. XIV. Tenyear incidence and progression of diabetic retinopathy. Arch Ophthalmol 112:1217-1228

8. Krolewski AS, Warram JH, Rand LI, Christlieb AR, Busick EJ, Kahn CR (1986) Risk of proliferative diabetic retinopathy in juvenile-onset type 1 diabetes: a 40-yr follow-up study. Diabetes Care 9:443-452

9. Palmberg P, Smith M, Waltman S et al (1981) The natural history of retinopathy in insulin-dependent juvenile onset diabetes. Ophthalmology 88:613-618

10. Klein R, Klein BE, Moss SE, Davis MD, DeMets DL (1984) The Wisconsin epidemiologic study of diabetic retinopathy. II. Prevalence and risk of diabetic retinopathy when age at diagnosis is less than 30 years. Arch Ophthalmol 102:520-526

11. Orchard TJ, Dorman JS, Maser RE et al (1990) Prevalence of complications in IDDM by sex and duration. Diabetes 39: 1116-1124

12. Hovind P, Tarnow L, Rossing K et al (2003) Decreasing incidence of severe diabetic microangiopathy in type 1 diabetes. Diabetes Care 26:1258-1264

13. Nordwall M, Bojestig M, Arnqvist HJ et al (2004) Declining incidence of severe retinopathy and persisting decrease of nephropathy in an unselected population of type 1 diabetesThe Linkøping Diabetes Complications Study. Diabetologia 47:1266-1272

14. Klein R, Klein BEK, Moss SE, Cruickshanks KJ (1998) The Wisconsin epidemiologic study of diabetic retinopathy: XVII. The 14-year incidence and progression of diabetic retinopathy and associated risk factors in type 1 diabetes. Ophthalmology 105:1801-1815

15. Joner G, Brinchmann-Hansen O, Torres CG, Hanssen KF (1992) A nationwide cross-sectional study of retinopathy and microalbuminuria in young Norwegian type 1 (insulin-dependent) diabetic patients. Diabetologia 35:1049-1054

16. Porta M, Sjolie AK, Chaturvedi N et al (2001) Risk factors for progression to proliferative diabetic retinopathy in the EURODIAB Prospective Complications Study. Diabetologia 44: 2203-2209

17. Donaghue KC, Craig ME, Chan AKF et al (2005) Prevalence of diabetes complications 6 years after diagnosis in an incident cohort of childhood diabetes. Diabet Med 22:711-718

18. Pirart J (1978) Diabetes mellitus and its degenerative complications: a prospective study of 4,000 patients observed between 1947 and 1973. Diabetes Care 1:168-188

19. Klein R, Klein BE, Moss SE, Davis MD, DeMets DL (1985) Retinopathy in young-onset diabetic patients. Diabetes Care $8: 311-315$

20. Kernell A, Dedorsson I, Johansson B et al (1997) Prevalence of diabetic retinopathy in children and adolescents with IDDM. A population-based multicentre study. Diabetologia 40:307-310

21. Joner G, Søvik O (1989) Increasing incidence of diabetes mellitus in Norwegian children 0-14 years of age 1973-1982. Diabetologia 32:79-83

22. Skrivarhaug T, Bangstad H-J, Stene LC, Sandvik L, Hanssen KF, Joner G (2006) Long-term mortality in a nationwide cohort of childhood-onset type 1 diabetic patients in Norway. Diabetologia 49:298-305

23. Wilkinson CP, Ferris FL, Klein RE et al (2003) Proposed international clinical diabetic retinopathy and diabetic macular edema disease severity scales. Ophthalmology 110:1677-1682

24. Mogensen CE (1987) Microalbuminuria as a predictor of clinical diabetic nephropathy. Kidney Int 31:673-689

25. DCCT Research Group (1993) The effect of intensive treatment of diabetes on the development and progression of long-term complications in insulin-dependent diabetes mellitus. N Engl J Med 329:977-986

26. Reichard P, Berglund B, Britz A, Cars I, Nilsson BY, Rosenqvist U (1991) Intensified conventional insulin treatment retards the microvascular complications of insulin-dependent diabetes mellitus (IDDM): the Stockholm Diabetes Intervention Study (SDIS) after 5 years. J Intern Med 230:101-108 
27. Brinchmann-Hansen O, Dahl-Jørgensen K, Sandvik L, Hanssen KF (1992) Blood glucose concentrations and progression of diabetic retinopathy: the seven year results of the Oslo study. BMJ 304:19-22

28. Klein R (1995) Hyperglycaemia and microvascular and macrovascular disease in diabetes. Diabetes Care 18:258-268

29. Davis MD, Fisher MR, Gangnon RE et al (1998) Risk factors for high-risk proliferative diabetic retinopathy and severe visual loss: Early Treatment Diabetic Retinopathy Study Report \#18. Invest Ophthalmol Vis Sci 39:233-252

30. Early Treatment Diabetic Retinopathy Study Research Group (1991) Fundus photographic risk factors for progression of diabetic retinopathy. ETDRS report No. 12. Ophthalmology 98:823-833

31. Early Treatment Diabetic Retinopathy Study Research Group (1991) Early photocoagulation for diabetic retinopathy ETDRS Report 9. Ophthalmology 98(Suppl 1):766-785

32. Kordonouri O, Danne T, Hopfenmuller W, Enders I, Hovender G, Weber B (1996) Lipid profiles and blood pressure: are they risk factors for the development of early background retinopathy and incipient nephropathy in children with insulin-dependent diabetes mellitus? Acta Paediatr 85:43-48

33. Larsson LI, Alm A, Lithner F, Dahlen G, Bergstrom R (1999) The association of hyperlipidemia with retinopathy in diabetic patients aged 15-50 years in the county of Umea. Acta Ophthalmol Scand 77:585-591

34. Verrotti A, Lobefalo L, Chiarelli $F$ et al (1997) Lipids and lipoproteins in diabetic adolescents and young adults with retinopathy. Eye 11:876-881

35. Sjolie AK, Stephenson JM, Aldington SJ et al (1997) Retinopathy and vision loss in insulin-dependent diabetes in Europe. The EURODIAB IDDM Complications Study. Ophthalmology 104:252-260

36. Lyons TJ, Jenkins AJ, Zheng D et al (2004) Diabetic retinopathy and serum lipoprotein subclasses in the DCCT/EDIC cohort. Invest Ophthalmol Vis Sci 45:910-918

37. Tesfaye S, Chaturvedi N, Simon EM et al (2005) Vascular risk factors and diabetic neuropathy. N Engl J Med 352:341-350
38. Stiko-Rahm A, Wiman B, Hamsten A, Nilsson J (1990) Secretion of plasminogen activator inhibitor-1 from cultured human umbilical vein endothelial cells is induced by very low density lipoprotein. Atherosclerosis 10:1067-1073

39. Yip J, Mattock MB, Morocutti A et al (1993) Insulin resistance in insulin-dependent diabetic patients with microalbuminuria. Lancet 342:883-887

40. Chaturvedi N, Sjolie AK, Porta M et al (2001) Markers of insulin resistance are strong risk factors for retinopathy incidence in type 1 diabetes. Diabetes Care 24:284-289

41. West KM, Erdreich LS, Stober JA (1980) Absence of a relationship between smoking and diabetic microangiopathy. Diabetes Care 3:250-252

42. Moss SE, Klein R, Klein BE (1991) Association of cigarette smoking with diabetic retinopathy. Diabetes Care 14:119-126

43. Muhlhauser I, Bender R, Bott U et al (1996) Cigarette smoking and progression of retinopathy and nephropathy in type 1 diabetes. Diabet Med 13:536-543

44. Chaturvedi N, Sjolie AK, Stephenson JM et al (1998) Effect of lisinopril on progression of retinopathy in normotensive people with type 1 diabetes. Lancet 351:28-31

45. Yusuf S, Sleight P, Pogue J et al (2000) Effects of an angiotensinconverting-enzyme inhibitor, ramipril, on cardiovascular events in high-risk patients. N Engl J Med 342:145-153

46. Estacio RO, Jeffers BW, Gifford N, Schrier RW (2000) Effect of blood pressure control on diabetic microvascular complications in patients with hypertension and type 2 diabetes. Diabetes Care 23 (Suppl 2):B54-B64

47. Klein R, Klein BEK, Moss SE, Davis MD, DeMets DL (1989) The Wisconsin epidemiologic study of diabetic retinopathy; IX. Fouryear incidence and progression of diabetic retinopathy when age at diagnosis is less than 30 years. Arch Ophthalmol 107:244-249

48. Mohan R, Kohner EM, Aldington SJ et al (1988) Evaluation of a non-mydriatic camera in Indian and European diabetic patients. Br J Ophthalmol 72:841-845

49. Kalm H (1992) Non-stereo photographic screening in long-term follow-up for detection of proliferative diabetic retinopathy. Acta Ophthalmol 70:228-234 